\title{
Lack of efficacy of blueberry in nutritional prevention of azoxymethane-initiated cancers of rat small intestine and colon Frank A Simmen*1,3, Julie A Frank ${ }^{3,5}$, Xianli Wu ${ }^{1,3}$, Rijin Xiao ${ }^{1,3,6}$, Leah J Hennings ${ }^{2}$ and Ronald L Prior ${ }^{3,4}$
}

Address: ${ }^{1}$ Department of Physiology and Biophysics, University of Arkansas for Medical Sciences, 4301 W. Markham Street, Little Rock, AR 72205, USA, ${ }^{2}$ Department of Pathology, University of Arkansas for Medical Sciences, 4301 W. Markham Street, Little Rock, AR 72205, USA, ${ }^{3}$ Arkansas Children's Nutrition Center, 15 Children's Way, Little Rock, AR 72205, USA, ${ }^{4}$ USDA Agricultural Research Service, 15 Children's Way, Little Rock, AR 72205, USA, ${ }^{5}$ Current address : Myeloma Institute for Research and Therapy, University of Arkansas for Medical Sciences, Little Rock, AR 72205 , USA and ${ }^{6}$ Current address : Center for Animal Nutrigenomics and Applied Animal Nutrition, Alltech Inc., Nicholasville, KY 40356, USA

Email: Frank A Simmen* - simmenfranka@uams.edu; Julie A Frank - JAFrank@uams.edu; Xianli Wu - WuXianli@uams.edu; RijinXiao - Rxiao@Alltech.com; Leah J Hennings - Lhennings@uams.edu; Ronald L Prior - RPrior@uams.edu

* Corresponding author

Published: 16 September 2009

BMC Gastroenterology 2009, 9:67 doi:10.1 186/147|-230X-9-67

This article is available from: http://www.biomedcentral.com/I47I-230X/9/67

(c) 2009 Simmen et al; licensee BioMed Central Ltd.

This is an Open Access article distributed under the terms of the Creative Commons Attribution License (http://creativecommons.org/licenses/by/2.0), which permits unrestricted use, distribution, and reproduction in any medium, provided the original work is properly cited.

\begin{abstract}
Background: Blueberries may lower relative risk for cancers of the gastrointestinal tract. Previous work indicated an inhibitory effect of consumed blueberry (BB) on formation of aberrant crypt foci (ACF) in colons of male Fisher F344 rats (inbred strain). However, effects of BB on colon tumors and in both genders are unknown.
\end{abstract}

Methods: We examined efficacy of BB in inhibition of azoxymethane (AOM)-induced colon ACF and intestine tumors in male and female Sprague-Dawley rats (outbred strain). Pregnant rats were fed a diet with or without $10 \%$ BB powder; progeny were weaned to the same diet as their dam and received $\mathrm{AOM}$ as young adults.

Results: Male and female rats on control diet had similar numbers of ACF at 6 weeks after AOM administration. $B B$ increased $(P<0.05)$ ACF numbers within the distal colon of female but not male rats. There was a significant $(P<0.05)$ diet by gender interaction with respect to total colon ACF number. Colon and duodenum tumor incidences were less in females than males at 17 weeks after AOM. BB tended $(0.1>P>0.05)$ to reduce overall gastrointestinal tract tumor incidence in males, however, tumor incidence in females was unaffected $(P>0.1)$ by BB. There was a tendency $(0.1>$ $P>0.05$ ) for fewer adenocarcinomas (relative to total of adenomatous polyps plus adenocarcinomas) in colons of female than male tumor-bearing rats; in small intestine, this gender difference was significant $(P<0.05)$. BB favored $(P<0.05)$ fewer adenocarcinomas and more adenomatous polyps (as a proportion of total tumor number) in female rat small intestine.

Conclusion: Results did not indicate robust cancer-preventive effects of BB. Blueberry influenced ACF occurrence in distal colon and tumor progression in duodenum, in gender-specific fashion. Data indicate the potential for slowing tumor progression (adenomatous polyp to adenocarcinoma) by BB. 


\section{Background}

Epidemiological findings generally indicate a lowering of relative risk of colorectal cancers in humans who regularly consume large amounts of fruits [1-7]. Conversely, individuals consuming relatively small amounts of fruits may have increased risk of colon cancer [8]. Fruit consumption lowers relative risk for cancers of the colon $[7,9,10]$, rectum [11], and small intestine [12]. Protective effects of fruits may be more robust for cancers of the colon than rectum $[2,10,13]$, may be stronger in distal than proximal colon sub-sites $[2,13,14]$, and in at least one study were more prominent in men than women [10]. Adenomatous polyps (adenomas), the precursors to colorectal adenocarcinomas, are less prevalent in high fruit consumers $[13,15]$. In addition, colorectal adenoma growth was inversely associated with consumption of fruits and berries [16]. In spite of the above, there are few epidemiological studies that have examined for effects of specific types of fruits and in particular berries on human colorectal cancer risk.

Berry fruits contain a diverse array of phytochemicals that may have human health benefits [17]. The possible colon cancer-preventive actions of berries have received recent interest [18]. Extracts of berries inhibited, in dose-dependent fashion, proliferation of human cancer cell lines [19]. Among the phenolic compounds of the blueberry (BB), the anthocyanins were shown to be the most potent inhibitors of cell proliferation and inducers of apoptosis when tested, in relatively pure form, on colon cancer cell lines [20,21]. In humans consuming blueberries, a significant portion of the ingested anthocyanins reach the colon [22] where they may contribute to tissue anti-oxidant capacity and hence, to anti-carcinogenesis. Additionally, consumption of BB results in postprandial increases in plasma antioxidant level in humans [23]. Pterostilbene, another phytochemical constituent of blueberry, impedes advancement of the cell cycle and induces apoptosis of human cancer cell lines in vitro [24].

In vivo studies of the colon cancer-preventive actions of berries have used the AOM-administered male Fisher 344 rat or the Apc ${ }^{\text {min }}$ mutant mouse. Freeze-dried black raspberries in the diet inhibited the size (and therefore development) of colon aberrant crypt foci (ACF) as well as tumor multiplicity in male Fisher 344 rats [25]. In this same animal model, blueberry suppressed the total number of colon ACF per rat [26], similar to that observed with $40 \mathrm{ppm}$ of pterostilbene added to diet [27]. In the $\mathrm{Apc}^{\mathrm{min}}$ mouse model, the blackberry anthocyanin, cyanidin-3-glucoside, as well as an anthocyanin enriched extract of bilberry decreased numbers of small intestine adenomas [28]. Also in $\mathrm{Apc}^{\mathrm{min}}$ mice, supplementation of diet with bilberry, lingonberry or cloudberry led to reductions in overall number and size of intestinal adenomas
[29]. Feeding tart cherries or anthocyanin extract of cherries to $\mathrm{Apc}^{\mathrm{min}}$ mice inhibited the frequency and size of intestine adenomas [30,31]. Thus, suppressive effects of berries on small intestine adenomas in $\mathrm{Apc}^{\text {min }}$ mice appear to be robust and consistent between studies.

Despite the above support for preventive effects of fruits and berries on colorectal cancers, several caveats remain. The in vitro studies typically observed effects of anthocyanins in the micromolar range, concentrations that may never be reached systemically or within the lumens of the small intestine or colon. The $\mathrm{Apc}^{\mathrm{min}}$ mouse does not model sporadic colon cancers, the most frequent type of colorectal cancer. The AOM-treated, inbred Fisher 344 male rat is highly sensitive to dietary and chemical manipulation of colon carcinogenesis and many structurally diverse molecules have been shown to inhibit or promote ACF and/or tumors in this model [32]. Therefore, results from the above animal models should be examined in outbred rat strains and in both genders.

Insulin and insulin resistance have been positively linked with AOM-induced carcinogenesis in rats $[33,34]$. Serum C-peptide, a bio-marker of insulin secretion, is positively associated with colorectal cancer risk in humans [35] and is regulated by dietary factors [36]; however, relevance of insulin to suppressive effects of fruit consumption on colorectal cancer development is unclear. In this study, we used a validated, AOM-treated Sprague-Dawley (outbred) rat model (males and females) to evaluate effects of $\mathrm{BB}$ on intestine tumor genesis and serum C-peptide. Results did not provide strong support for cancer-preventive effects of $\mathrm{BB}$ in the rat colon.

\section{Methods \\ Materials}

Freeze-dried, powdered blueberry ['HiActives' Wild Blueberry Powder, Lot \#01351573, derived from wild blueberries (Vaccinium angustifolium)] was obtained from FutureCeuticals Inc. (Momence, IL). Composition of blueberry (BB) powder was $2.73 \%$ protein, $5.5 \%$ fiber, $3.08 \%$ fat and $2.96 \%$ moisture. BB contained over 20 individual anthocyanins; the total amount of anthocyanins was $\sim 28 \mathrm{mg} / \mathrm{g}$ dry weight. AIN-93G diets were formulated as in Table 1 . The $10 \%$ BB dose was chosen in order to maximize consumption of anthocyanins and without significantly affecting food consumption when compared to the control diet.

\section{Animals}

Animal use protocols were approved by the University of Arkansas for Medical Sciences Institutional Animal Care and Use Committee. The experiment was designed to examine effects of "lifetime" BB diet exposure (including prenatal and pre- and post-weaning periods) on 
Table I: Experimental AIN-93G diets

\begin{tabular}{lcc}
\hline Component (g/kg) & Control & Blueberry (BB) \\
\hline Casein & 200 & 196.3 \\
L-Cystine & 3 & 3 \\
Corn Starch & 397.5 & 310.3 \\
Maltodextrin & 132 & 132 \\
Sucrose & 100 & 100 \\
Corn Oil & 70 & 69 \\
Cellulose & 50 & 41.9 \\
AIN93G Mineral Mix & 35 & 35 \\
AIN93G Vitamin Mix & 10 & 10 \\
Choline Bitartrate & 2.5 & 2.5 \\
TBHQ & 0.014 & 0.014 \\
Blueberry Powder & 0 & 100 \\
Total & 1000 & 1000 \\
\hline
\end{tabular}

azoxymethane (AOM)-induced carcinogenesis. This experimental design is presented in Figure 1. Forty-four pregnant (gestation day 4) Sprague-Dawley rat dams (Charles River Laboratories; Wilmington, MA) were received in the Association for Assessment and Accreditation of Laboratory Animal Care - approved animal facility at the Arkansas Children's Hospital Research Institute. Dams were immediately placed on diets [Control $(\mathrm{n}=22)$ or $10 \% \mathrm{BB}(\mathrm{n}=22)]$. At postnatal day (PND) 3, pups were weighed and litters culled to five males and five females. Pups were weaned at PND 21 and given the same diet as their dam for the duration of the experiment. After lactation, dams were used for studies not described here. Some offspring (randomly selected) were used for studies of adiposity and metabolism that also were outside the purview of the present focus and hence are not described here. Animals were housed in polycarbonate cages and permitted ad libitum access to food and water. Animal rooms were temperature- and humidity-controlled with a 12-h lightdark cycle.

\section{Tumors and ACF}

AOM (Midwest Research Institute; Kansas City, MO) was administered subcutaneously ( $15 \mathrm{mg} / \mathrm{kg}$ body weight) to offspring at PND 53 and again at PND 60. Animals were weighed weekly throughout the duration of the experiment. ACF are observed in the colon mucosa during AOM-induced colon tumorigenesis and are used as an intermediate end point to evaluate cancer-prevention by nutritional and chemo-preventive factors [32]. Colons were obtained from 15 randomly selected animals of each diet group and gender at 6 weeks after the second AOM administration and used for visualization of ACF. Each colon was divided into three equal-length segments, designated as proximal, mid or distal. Segments were stained with $0.2 \%$ methylene blue in PBS for 3-5 minutes, rinsed with phosphate-buffered saline (PBS) for 1-2 minutes, and placed in $0.4 \%$ formalin-PBS. ACF were visualized using a Nikon AMZ800 stereoscope $(40 \times$ magnification) by a single observer blinded to treatment. ACF were elevated (single or multiple clustered) crypts with elongated and enlarged openings. The regional assignment of each ACF and number of crypts per ACF were recorded [37].

At 16 weeks post-AOM, a group of 10 animals from each diet group and gender were randomly chosen and subjected to necropsy for confirmation of tumor presence. At 17 weeks post-AOM, the liver, stomach, spleen, small intestine, cecum, colon and rectum from 73 or 74 animals of each diet group and gender were obtained and inspected for presence of tumors. Tumor location was determined relative to the distal end of the colon or small intestine. Tumors were removed, weighed, marked on the

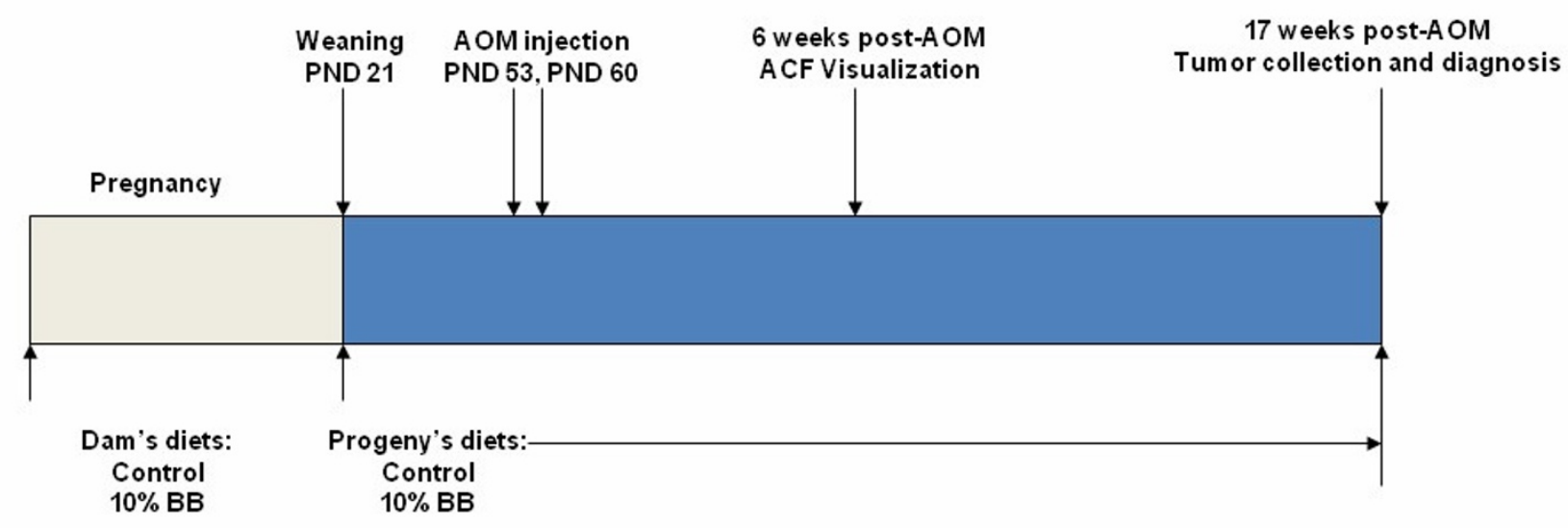

Figure I

Experimental design. Gastrointestinal tissues were collected at 6 and 17 weeks after the second AOM administration for determination of ACF and tumors, respectively. PND, postnatal day. 
serosal surface with India ink, and placed in formalin. Serum was prepared from each animal. Pancreas and liver weights were recorded.

Small intestine and colon tumors were classified as adenomatous polyp (adenomatous polyp or adenomatous polyp with carcinoma in situ) or adenocarcinoma (invasive adenocarcinoma, invasive mucinous carcinoma, or metastatic adenocarcinoma with signet ring features) as described previously [36]. Diagnostic features of adenomatous polyps were well differentiated epithelial cells with low mitotic rate and absence of invasion. Adenocarcinomas were poorly differentiated, with cellular and nuclear pleomorphism, high mitotic rate, and evidence of invasion. Some colons manifested nodules which had a tumor-like appearance on gross examination, but which were comprised of focal areas/aggregates of lymphoid B and T cells [38]. These lesions, as well as the few observed mammary, liver, spleen, stomach, cecal and rectal tumors were excluded from statistical analysis.

\section{C-peptide}

Serum C-peptide levels were measured using a rat C-peptide radioimmunoassay (Linco Research, Inc, St. Charles, MO). Sera $(100 \mu \mathrm{l})$ from $\mathrm{n}=12$ to 14 animals of each diet group and each gender at 17 weeks post-AOM were assayed in duplicate in two replicate assays. Sensitivity of the assay was $25 \mathrm{pM}$ and the inter-assay variation was less than $10 \%$.

\section{Statistics}

Statistical analysis was performed using SigmaStat for Windows, version 3.11 (Systat Software, Inc., Richmond, CA). BB effects on AOM-induced tumor incidence at 17 weeks post-AOM were examined by $\chi^{2}$ analysis. Tumor pathology was compared for effects of diet and gender using Fisher's Exact Test. The effects of BB on colon ACF number and ACF crypt multiplicity (number of crypts per ACF) were evaluated by Student's $t$ test or the Mann-Whitney rank sum test, the latter when data were not normally distributed. The interaction between effects of diet and gender on ACF was determined using two-way ANOVA. Effects of BB on serum C-peptide concentration were evaluated using Student's $t$ test. All values are presented as means \pm S.E.M. Differences between means were considered to be significant at $P<0.05$, whereas $0.1>P>0.05$ was considered to represent a tendency for a difference.

\section{Results}

As expected, female rats gained less weight over time than did male rats (Figure 2); presumably due to gender differences in locomotor activity, blood androgen levels, insulin sensitivity and nutrient uptake/utilization, among other physiological differences. However, inclusion of BB to the diet had no effect on body weight accretion by rats of either gender (Figure 2); indicating no effect of BB on food consumption by either sex. BB had no effect on lengths of colon or rectum or weights of pancreas or liver (tissue weights were normalized to body weight) within each gender at 17 weeks post-AOM (data not shown). BB also had no effect on serum C-peptide concentration, an indicator of steady-state insulin secretion; however, Cpeptide levels were $30 \%$ lower for female compared to male rats (data not shown). Tumor status (presence or absence of tumors) had no effect on C-peptide concentration.

At 6 weeks after the second AOM treatment, male and female rats on the control diet had similar numbers of ACF (Tables 2, 3). ACF were most prevalent in mid, followed by distal colon; while proximal colons had fewer ACF. Addition of BB to the diet resulted in fewer ACF in mid and distal colons of male rats; however, results were not statistically significant (Table 2). Contrary to our hypothesis, BB consumption led to increased $(P<0.05)$ ACF numbers within the distal region of female rat colons (Table 2). ACF data were grouped by size, summed for each colon, and analyzed for effects of diet (Table 3). There was a tendency $(0.1>P>0.05)$ for a $\sim 24 \%$ reduction in total number of ACF in the colons of BB-fed male rats. In female rats, $\mathrm{BB}$ tended $(0.1>P>0.05)$ to increase (by $\sim 30 \%$ ) the number of small ACF (Table 3). A significant $(P<0.05)$ gender by diet interaction was observed for occurrence of small and small plus large ACF (Table 3). BB and gender did not affect ACF crypt multiplicity (no. crypts per ACF) in male or female rat colons (Table 3 ).

We evaluated tumor parameters at 17 weeks after AOM treatments, a time-point when tumors are prevalent in large and small intestines of this animal model (39). Colon tumor incidence was lower in female compared to male rats, regardless of diet (Table 4). Tumor incidence in small intestines (duodenum) also was reduced for female rats, regardless of diet. Comparing data summed for all segments of the colon and small intestine, BB tended ( 0.1 $>P>0.05$ ) to reduce tumor incidence in males (Table 4). In contrast, tumor incidence in female rat colon and small intestine was unaffected $(P>0.1)$ by BB (Table 4$)$.

BB had no effect on tumor multiplicity (\# tumors per tumor-bearing rat) in colon or small intestine and this measure was also unaffected by gender (Figure 3A, B). Similarly, no differences in tumor weight were apparent between diets or gender (data not shown). The ratio of number of adenocarcinomas to the total number of adenomatous polyps plus adenocarcinomas was determined as an index of tumor progression. In the colon, there was a tendency for fewer adenocarcinomas in female than male rats; in small intestine, the gender difference was significant $(P<0.05)$ (Figure $3 \mathrm{C}, \mathrm{D})$. BB diet favored fewer 


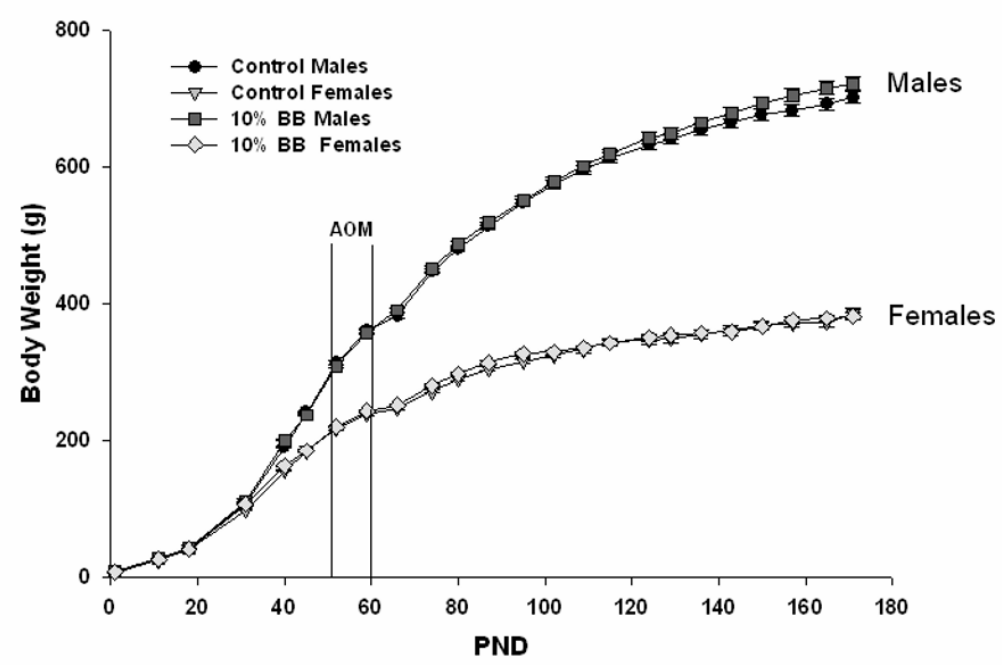

Figure 2

Postnatal growth of experimental animals. Body weights (mean and SEM) are shown. PND, postnatal day.

adenocarcinomas and more adenomas (as a proportion of total tumor numbers) in female rat small intestine $(P<$ $0.05)$.

\section{Discussion}

Our results did not provide strong support for a beneficial role of $\mathrm{BB}$ in inhibition of AOM-induced intestinal cancers in Sprague-Dawley rats. $\mathrm{BB}$ only tended to reduce the total number of colon ACF and overall intestine tumor incidence and only in males. In female rats, BB augmented ACF numbers in distal colon, contrary to the hypothesized protective action. The non-significant tendency for a reduced number of ACF in male Sprague-Dawley rats consuming $\mathrm{BB}$ diet somewhat agrees with findings by Boateng et al., 2007 [26], who studied male Fisher 344 rats. However, the latter group reported a statistically significant and robust suppression of ACF by BB diet, in contrast to that observed here. This difference between studies may reflect the two rat strains used, the differences in group size ( $n=6$ animals for previous study, $n=15$ ani- mals for present study), and/or the differing amounts of blueberry incorporated in the diet $(10 \%$ in the present study, $5 \%$ in the previous study). With regard to differences in dietary content of blueberry, we do not consider this a likely cause of the study differences, since anthocyanins suppressed adenoma formation in a linear dosedependent fashion in Apc min mice [28]. It is plausible that Sprague-Dawley rats are less susceptible (and/or individually more variable) to dietary influences on AOM-induced ACF and tumor formation than inbred Fisher 344 rats, which also may contribute to differences between studies. In marked contrast to these findings was the significant increase in ACF occurrence in distal colon of female rats consuming $\mathrm{BB}$. The basis for this novel, gender-specific response to $\mathrm{BB}$ is unknown, albeit, we speculate that this may involve functional interactions of BB constituent(s) with female sex hormones and/or receptors.

Regional distribution of adenocarcinomas closely followed that for ACF, as in our prior studies [36,37,39]. Spe-

Table 2: Colon ACF number (per rat) at 6 weeks after second carcinogen treatment.

\begin{tabular}{|c|c|c|c|c|}
\hline \multirow[b]{2}{*}{ Region } & \multicolumn{2}{|c|}{ Male } & \multicolumn{2}{|c|}{ Female } \\
\hline & Control & $10 \%$ BB & Control & $10 \%$ BB \\
\hline Proximal Colon & $1.9 \pm 0.6$ & $2.2 \pm 0.7$ & $2.4 \pm 0.8$ & $2.7 \pm 0.8$ \\
\hline Middle Colon & $92.7 \pm 12.6$ & $74.3 \pm 9.0$ & $77.7 \pm 11.8$ & $103.1 \pm 9.9$ \\
\hline Distal Colon & $47.1 \pm 5.6$ & $34.7 \pm 3.0$ & $42.1 \pm 5.4 \mathrm{a}$ & $58.1 \pm 5.3 b$ \\
\hline
\end{tabular}

a, bindicate a significant difference between groups $(P<0.05) ; \mathrm{n}=15$ animals of each gender for each diet group. 
Table 3: Colon ACF number and multiplicity at 6 weeks postAOM *

\begin{tabular}{|c|c|c|}
\hline & Male & Female \\
\hline \multicolumn{3}{|l|}{ Number of Small ACF } \\
\hline Control & $129.5 \pm 15.4$ & $117.6 \pm 15.1 \mathrm{a}$ \\
\hline $10 \% \mathrm{BB}$ & $99.9 \pm 8.9$ & $152.8 \pm 11.9 \mathrm{~b}$ \\
\hline Interaction between diet and gender & \multicolumn{2}{|c|}{$P=0.016$} \\
\hline \multicolumn{3}{|l|}{ Number of Large ACF } \\
\hline Control & $12.2 \pm 2.4$ & $7.1 \pm 2.5$ \\
\hline $10 \% \mathrm{BB}$ & $8.1 \pm 1.7$ & $10.1 \pm 2.2$ \\
\hline Interaction between diet and gender & \multicolumn{2}{|c|}{ NS } \\
\hline \multicolumn{3}{|l|}{ Total Number of ACF } \\
\hline Control & $141.7 \pm 16.7 \mathrm{a}$ & $124.7 \pm 15.2 \mathrm{a}$ \\
\hline $10 \% \mathrm{BB}$ & $107.9 \pm 10.0 b$ & $162.8 \pm 12.8 b$ \\
\hline Interaction between diet and gender & \multicolumn{2}{|c|}{$P=0.012$} \\
\hline \multicolumn{3}{|l|}{ ACF Crypt Multiplicity } \\
\hline Control & $2.1 \pm 0.1$ & $1.9 \pm 0.1$ \\
\hline $10 \% \mathrm{BB}$ & $2.0 \pm 0.1$ & $1.9 \pm 0.1$ \\
\hline Interaction between diet and gender & \multicolumn{2}{|c|}{ NS } \\
\hline
\end{tabular}

*Small ACF includes those with I, 2 or 3 crypts; large ACF are those with 4 or more crypts; total $A C F=$ no. small $A C F+$ no. large $A C F$; ACF crypt multiplicity $=$ no. of crypts per $A C F$.

a, b within a column represents $0.1>P>0.05$, student's t-test; also shown are $P$ values for overall interaction between diet and gender as determined by two-way ANOVA.

$\mathrm{n}=15$ animals per gender for each diet group.

NS: $P>0.1$ cifically, ACF and tumors were more prevalent in mid > distal > proximal colon. Several epidemiological studies reported more pronounced cancer-protective effects of fruits in distal rather than proximal colon of humans $[2,13,14]$. The functional correspondence of the mid colon of the rat to one or more sub-sites of the human colon is not known; anatomically, it corresponds to transverse and upper distal regions of the human colon. The lack of inhibitory effect of $\mathrm{BB}$ on tumorigenesis in the rat colon may suggest that $\mathrm{BB}$ will not be preventive for human colon cancers, although epidemiological studies are necessary to resolve this question.

The similar ACF numbers for male and female rats on control diet, but less frequently occurring colon tumors in females relative to males, were noted. Thus, progression of ACF to adenomatous polyps may be slowed or partially blocked in female rats or alternatively, ACF in female rats may regress to a greater extent during the later stages of tumorigenesis, also leading to fewer polyps. Such mechanisms have a precedent in the case of AOM-treated AKR/J mice which are resistant to colon tumor-formation but manifest ACF in their colons [40]. Striking differences in tumor incidence with gender were maintained across the three regions of the colon as well as proximal small intestine (duodenum). This is consistent with previous observations of greater tumor incidence in male than female rats after administration of colon carcinogens [41-43]. Since ACF numbers were similar for males and female Sprague-Dawley rats on control diet, liver activation of AOM to the proximate carcinogen, methylazoxymethanol

Table 4: Incidence of AOM-induced tumors at 17 weeks post-AOM *

\begin{tabular}{|c|c|c|c|c|c|}
\hline \multirow[b]{2}{*}{ \# rats per group } & \multicolumn{2}{|c|}{ Male } & \multicolumn{2}{|c|}{ Female } & \\
\hline & $\begin{array}{l}\text { Control } \\
\text { (73) }\end{array}$ & $\begin{array}{c}10 \% \text { BB } \\
\text { (74) }\end{array}$ & $\begin{array}{c}\text { Control } \\
\text { (74) }\end{array}$ & $\begin{array}{c}10 \% \text { BB } \\
(74)\end{array}$ & \multirow[b]{2}{*}{ Gender effect } \\
\hline & & & & & \\
\hline Proximal colon & $5.5(4)$ & $4.1(3)$ & $1.4(1)$ & $2.7(2)$ & NS \\
\hline Middle colon & $31.5(23)$ & $20.3(15)$ & $8.1(6)$ & $10.8(8)$ & $P<0.001$ \\
\hline Distal colon & $10.9(8)$ & $10.8(8)$ & $0(0)$ & $2.7(2)$ & $P<0.01$ \\
\hline Entire colon & $41.1(30)$ & $29.7(22)$ & $9.5(7)$ & $16.2(12)$ & $P<0.001$ \\
\hline Proximal SI ** & $23.3(17)$ & $12.2(9)$ & $6.8(5)$ & $6.8(5)$ & $P<0.01$ \\
\hline Middle SI & $1.4(\mathrm{I})$ & $1.4(\mathrm{I})$ & $0(0)$ & $0(0)$ & NS \\
\hline Distal SI & $0(0)$ & $0(0)$ & $0(0)$ & $0(0)$ & NS \\
\hline Entire SI & $24.7(18)$ & $13.5(10)$ & $6.8(5)$ & $6.8(5)$ & $P<0.01$ \\
\hline Colon + SI & $56.2(4 I)^{a}$ & $41.8(31)^{b}$ & $16.2(12)$ & $23.0(17)$ & $P<0.001$ \\
\hline
\end{tabular}

* Incidence is percentage of tumor-bearing animals; actual number of animals with each tumor is shown in parentheses; gender effects were calculated from combined diet groups; six rectal tumors, two mammary tubular adenomas, one biliary cystadenoma, two cecal tumors, one stomach tumor, one spleen tumor, and a number of nodules representing focal areas of lymphoid hyperplasia [38] also were found; all were excluded from calculations of small intestine and colon tumor indices.

** SI: small intestine (almost all tumors were found in duodenum; with the exception of two in the jejunum).

$\mathrm{a}, \mathrm{b}$ indicate a tendency for a difference $(P=0.08 \mathrm{I})$; NS: $P>0.1$ 
A
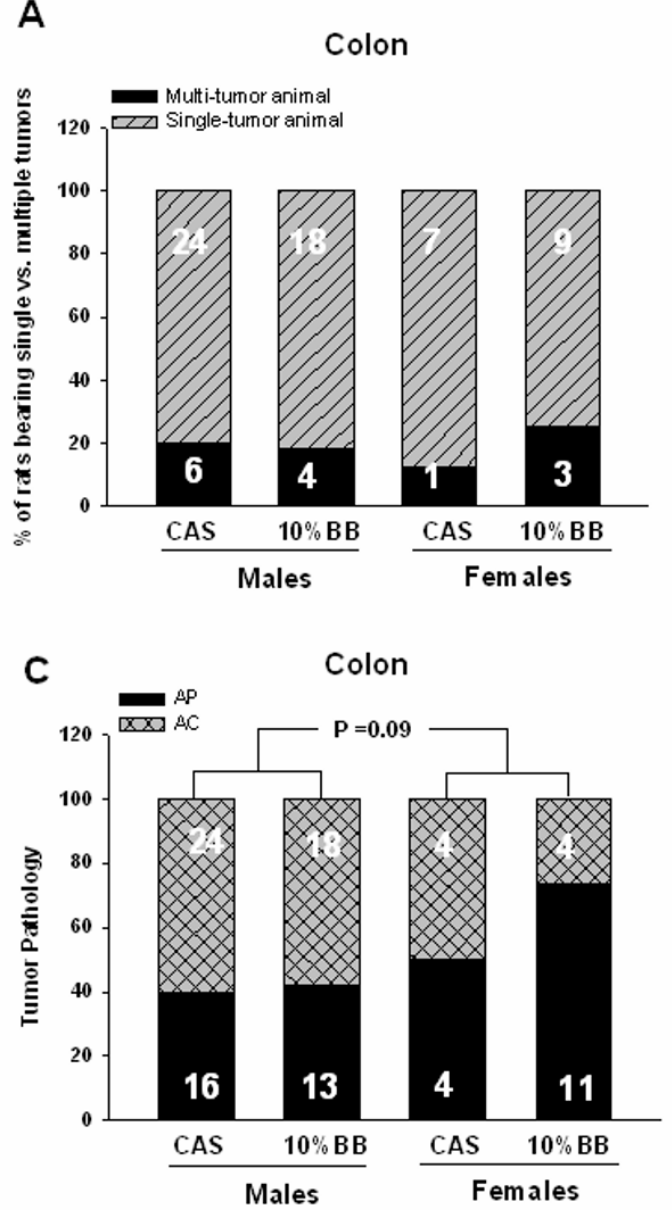

B
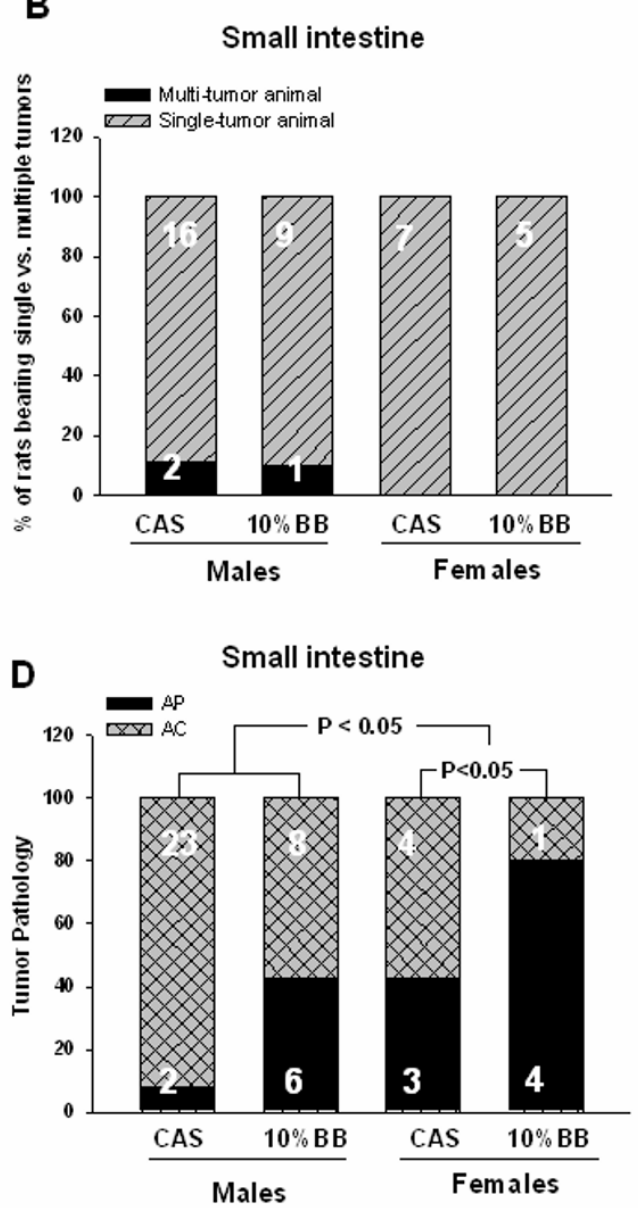

Figure 3

Tumor multiplicity and tumor pathology for experimental animals. The relative proportion of tumor-bearing animals having single or multiple $(>I)$ tumors in the colon $(A)$ or small intestine $(B)$ was determined. Relative proportion of tumors classified as adenomatous polyps (AP) or adenocarcinomas (AC, this group also included $A C$ with signet ring features) in colon $(C)$ and small intestine $(D)$ is presented as percentage of $A P+A C . n=73$ (control male rats) or $n=74$ ( $10 \%$ BB male and female rats, control female rats). Actual numbers of animals having one or greater than one tumor also is indicated in $A$ and $B$. Actual numbers of $A P$ and $A C$ tumors also are indicated in $C$ and $D$.

[44] likely does not differ with gender. Rather, the involvement of systemic or local factor(s) that affect postinitiation phases of intestinal tumorigenesis and which exhibit sexual dimorphism is suggested. We speculate that insulin may be one such factor, since C-peptide levels were significantly lower in female rats (presumably as a consequence of their increased insulin sensitivity) and insulin (and insulin resistance) have been positively linked with AOM carcinogenesis in rats $[33,34]$. Interestingly, incidence of colorectal cancer is slightly lower in women than men [45]. Thus, a further understanding of how gender affects tumorigenesis in this animal model may be relevant to elucidating endocrine and other influences on human colorectal cancer incidence rates.
Regional differences in tumor incidence within the colon and small intestine have been reported $[36,37,39,46,47]$ and were confirmed here. Another laboratory has shown in male Sprague-Dawley rats that AOM induces DNA modifications (alkylation) to similar extents in proximal and distal halves of the colon; however, the distal half of the colon responds to these DNA modifications with a greater degree of apoptosis and DNA repair, compared to proximal colon [46]. In view of the known apoptosisinducing effects of anthocyanins and stilbenes in vitro, we hypothesized that these molecules, when provided via $\mathrm{BB}$ diet, would promote apoptosis of colon epithelial cells whose DNA was newly modified by AOM during initiation of carcinogenesis, thus resulting in fewer ACF and 
tumors. However, our ACF and tumor results did not support this hypothesized action. Perhaps, the levels of these bio-active factors within the microenvironment of the colonic crypt and luminal epithelium were limiting.

Consumption of fruits may protect against cancer development in human small intestine [12]. Indeed, we observed that BB inhibited the adenoma-adenocarcinoma transition in female rat duodenum. This is generally concordant with the reported inhibition, by fruit consumption, of colorectal adenoma growth in humans $[13,15,16]$ and the rather consistent inhibition by berries of adenoma growth in Apc min mice [29-31]. In the latter model, adenomas are common in small intestine. Thus, collective findings highlight the potential for use of berries and fruits in dietary prevention of small intestine tumors.

In vitro and in vivo studies implicate anthocyanins and other phytochemicals in growth-inhibition of cancerous cells $[20,21,24,27]$. Such molecules may have estrogenic or anti-estrogenic actions [48] which may pertain to the gender-specificity of effects observed, although this is speculative. Further studies that examine how BB components affect the adenoma-adenocarcinoma transition, and how this is affected by gender, may yet reveal approaches for cancer-prevention using whole $\mathrm{BB}$ or its constituent(s), alone or in combination with other colon cancerpreventive foods or factors.

\section{Conclusion}

Results did not demonstrate robust cancer-preventive effects of BB but identified marked gender differences in incidence of AOM-induced tumors. Blueberry influenced, in gender-specific fashion, ACF occurrence in distal colon and tumor progression in duodenum. These findings illustrate the complex interplay of bio-active dietary factors, gender, tissue sub-site, and endocrine status in intestinal carcinogenesis and neoplasia.

\section{Abbreviations}

BB: blueberry; AOM: azoxymethane; ACF: aberrant crypt foci; PBS: phosphate-buffered saline.

\section{Competing interests}

The authors declare that they have no competing interests.

\section{Authors' contributions}

FAS and RLP conceived and planned the study. FAS drafted the manuscript. JAF quantified ACF, performed Cpeptide assays and analyzed the data. XW helped with experimental planning and diet formulation. RX participated in tumor collection and performed data analysis. LJH conducted all pathology. All authors provided input during manuscript revision and all authors read and approved the final manuscript.

\section{Acknowledgements}

Dr. Rosalia C.M. Simmen provided many helpful suggestions during the course of this work and a critical review of the manuscript. This work was supported by the U.S. Department of Agriculture (CRIS 625I-51000-00503S). Research was performed, in part, using compound(s) provided by the National Cancer Institute's Chemical Carcinogen Reference Standards Repository operated under contract by Midwest Research Institute, no. N02-CB-07008.

\section{References}

I. Levi F, Pasche C, La Vecchia C, Lucchini F, Franceschi S: Food groups and colorectal cancer risk. Br J Cancer 1999, 79: I 283-87.

2. Voorrips LE, Goldbohm RA, van Poppel G, Sturmans F, Hermus RJ, Brandt PA van den: Vegetable and fruit consumption and risks of colon and rectal cancer in a prospective cohort study: The Netherlands Cohort Study on Diet and Cancer. Am J Epidemiol 2000, 152:1081-92.

3. Terry P, Giovannucci E, Michels KB, Bergkvist L, Hansen H, Holmberg $L$, Wolk $A$ : Fruit, vegetables, dietary fiber, and risk of colorectal cancer. J Natl Cancer Inst 200I, 93:525-33.

4. Lock K, Pomerleau J, Causer L, Altmann DR, McKee M: The global burden of disease attributable to low consumption of fruit and vegetables: implications for the global strategy on diet. Bull World Health Organ 2005, 83:100-8.

5. Lin J, Zhang SM, Cook NR, Rexrode KM, Liu S, Manson JE, Lee IM, Buring JE: Dietary intakes of fruit, vegetables, and fiber, and risk of colorectal cancer in a prospective cohort of women (United States). Cancer Causes Control 2005, 16:225-33.

6. Park Y, Subar AF, Kipnis V, Thompson FE, Mouw T, Hollenbeck A, Leitzmann MF, Schatzkin A: Fruit and vegetable intakes and risk of colorectal cancer in the NIH-AARP diet and health study. Am J Epidemiol 2007, 166: 170-80.

7. Diergaarde B, Braam H, Vasen HF, Nagengast FM, van Muijen GN, Kok FJ, Kampman E: Environmental factors and colorectal tumor risk in individuals with hereditary nonpolyposis colorectal cancer. Clin Gastroenterol Hepatol 2007, 5:736-42.

8. McCullough ML, Robertson AS, Chao A, Jacobs EJ, Stampfer MJ, Jacobs DR, Diver WR, Calle EE, Thun MJ: A prospective study of whole grains, fruits, vegetables and colon cancer risk. Cancer Causes Control 2003, 14:959-70.

9. Wark PA, Weijenberg MP, van't Veer P, van Wijhe $G$, Lüchtenborg M, van Muijen GN, de Goeij AF, Goldbohm RA, Brandt PA van den: Fruits, vegetables, and hMLHI protein-deficient and -proficient colon cancer: The Netherlands cohort study. Cancer Epidemiol Biomarkers Prev 2005, 14:1619-25.

10. Nomura AM, Wilkens LR, Murphy SP, Hankin JH, Henderson BE, Pike MC, Kolonel LN: Association of vegetable, fruit, and grain intakes with colorectal cancer: the Multiethnic Cohort Study. Am J Clin Nutr 2008, 88:730-37.

II. Slattery ML, Curtin KP, Edwards SL, Schaffer DM: Plant foods, fiber, and rectal cancer. Am J Clin Nutr 2004, 79:274-8I.

12. Negri E, Bosetti C, La Vecchia C, Fioretti F, Conti E, Franceschi S: Risk factors for adenocarcinoma of the small intestine. Int J Cancer 1999, 82:171-74.

13. Millen AE, Subar AF, Graubard BI, Peters U, Hayes RB, Weissfeld JL, Yokochi LA, Ziegler RG, PLCO Cancer Screening Trial Project Team: Fruit and vegetable intake and prevalence of colorectal adenoma in a cancer screening trial. Am J Clin Nutr 2007, 86: $1754-64$.

14. Koushik A, Hunter DJ, Spiegelman D, Beeson WL, Brandt PA van den, Buring JE, Calle EE, Cho E, Fraser GE, Freudenheim JL, Fuchs CS, Giovannuci EL, Goldbohm RA, Harnack L, Jacobs DR Jr, Kato I, Krogh V, Larsson SC, Leitzmann MF, Marshall JR, McCullough ML, Miller AB, Pietinen P, Rohan TE, Schatzkin A, Sieri S, Virtanen MJ, Wolk A, Zeleniuch-Jacquotte A, Zhang SM, Smith-Warner SA: Fruits, vegetables, and colon cancer risk in a pooled analysis of 14 cohort studies. J Natl Cancer Inst 2007, 99: I 47 I-83.

15. Michels KB, Giovannucci E, Chan AT, Singhania R, Fuchs CS, Willett WC: Fruit and vegetable consumption and colorectal adenomas in the Nurses' Health Study. Cancer Res 2006, 66:3942-53.

16. Almendingen K, Hofstad B, Vatn MH: Dietary habits and growth and recurrence of colorectal adenomas: results from a three-year endoscopic follow-up study. Nutr Cancer 2004, 49: $|3|-38$. 
17. Prior RL, Wu X: Anthocyanins: structural characteristics that result in unique metabolic patterns and biological activities. Free Radic Res 2006, 40:1014-28.

18. Stoner GD, Wang LS, Zikri N, Chen T, Hecht SS, Huang C, Sardo C Lechner JF: Cancer prevention with freeze-dried berries and berry components. Semin Cancer Biol 2007, I 7:403-I0.

19. Seeram NP, Adams LS, Zhang Y, Lee R, Sand D, Scheuller HS, Heber D: Blackberry, black raspberry, blueberry, cranberry, red raspberry, and strawberry extracts inhibit growth and stimulate apoptosis of human cancer cells in vitro. J Agric Food Chem 2006, 54:9329-39.

20. Yi W, Fischer J, Krewer G, Akoh CC: Phenolic compounds from blueberries can inhibit colon cancer cell proliferation and induce apoptosis. J Agric Food Chem 2005, 53:7320-29.

21. Srivastava A, Akoh CC, Fischer J, Krewer G: Effect of anthocyanin fractions from selected cultivars of Georgia-grown blueberries on apoptosis and phase II enzymes. J Agric Food Chem 2007, 55:3180-85.

22. Kahle K, Kraus M, Scheppach W, Ackermann M, Ridder F, Richling E: Studies on apple and blueberry fruit constituents: do the polyphenols reach the colon after ingestion? Mol Nutr Food Res 2006, 50:418-23.

23. Prior RL, Gu L, Wu X, Jacob RA, Sotoudeh G, Kader AA, Cook RA Plasma antioxidant capacity changes following a meal as a measure of the ability of a food to alter in vivo antioxidant status. I Am Coll Nutr 2007, 26: |70-8|

24. Pan MH, Chang YH, Badmaev V, Nagabhushanam K, Ho CT: Pterostilbene induces apoptosis and cell cycle arrest in human gastric carcinoma cells. J Agric Food Chem 2007, 55:7777-85.

25. Harris GK, Gupta A, Nines RG, Kresty LA, Habib SG, Frankel WL, LaPerle K, Gallaher DD, Schwartz SJ, Stoner GD: Effects of lyophilized black raspberries on azoxymethane-induced colon cancer and 8-hydroxy-2'-deoxyguanosine levels in the Fischer 344 rat. Nutr Cancer 200I, 40:125-33.

26. Boateng J, Verghese M, Shackelford L, Walker LT, Khatiwada J, Ogutu S, Williams DS, Jones J, Guyton M, Asiamah D, Henderson F, Grant L, DeBruce M, Johnson A, Washington S, Chawan CB: Selected fruits reduce azoxymethane (AOM)-induced aberrant crypt foci (ACF) in Fisher 344 male rats. Food Chem Toxicol 2007 45:725-32.

27. Suh N, Paul S, Hao X, Simi B, Xiao H, Rimando AM, Reddy BS: Pterostilbene, an active constituent of blueberries, suppresses aberrant crypt foci formation in the azoxymethane-induced colon carcinogenesis model in rats. Clin Cancer Res 2007 I 3:350-55.

28. Cooke D, Schwarz M, Boocock D, Winterhalter P, Steward WP, Gescher AJ, Marczylo TH: Effect of cyanidin-3-glucoside and an anthocyanin mixture from bilberry on adenoma development in the ApcMin mouse model of intestinal carcinogenesis--relationship with tissue anthocyanin levels. Int J Cancer 2006, I I 9:2213-20

29. Misikangas M, Pajari AM, Päivärinta E, Oikarinen SI, Rajakangas J, Marttinen $M$, Tanayama H, Törrönen R, Mutanen M: Three Nordic berries inhibit intestinal tumorigenesis in multiple intestinal neoplasia/+ mice by modulating beta-catenin signaling in the tumor and transcription in the mucosa. I Nutr 2007, 1 37:2285-90.

30. Kang SY, Seeram NP, Nair MG, Bourquin LD: Tart cherry anthocyanins inhibit tumor development in Apc Min mice and reduce proliferation of human colon cancer cells. Cancer Lett 2003, 194:13-9.

31. Bobe G, Wang B, Seeram NP, Nair MG, Bourquin LD: Dietary anthocyanin-rich tart cherry extract inhibits intestinal tumorigenesis in APC(Min) mice fed suboptimal levels of sulindac. J Agric Food Chem 2006, 54:9322-28.

32. Corpet DE, Taché S: Most effective colon cancer chemopreventive agents in rats: a systematic review of aberrant crypt foci and tumor data, ranked by potency. Nutr Cancer 2002, 43: $|-2|$.

33. Tran TT, Medline A, Bruce WR: Insulin promotion of colon tumors in rats. Cancer Epidemiol Biomarkers Prev 1996, 5: I013-15.

34. Xiao R, Su Y, Simmen RCM, Simmen FA: Dietary soy protein inhibits DNA damage and cell survival of colon epithelial cells through attenuated expression of fatty acid synthase. Am J Physiol Gastrointest Liver Physiol 2008, 294:G868-76.
35. Pisani P: Hyper-insulinaemia and cancer, meta-analyses of epidemiological studies. Arch Physiol Biochem 2008, I I 4:63-70.

36. Xiao R, Carter JA, Linz AL, Ferguson M, Badger TM, Simmen FA: Dietary whey protein lowers serum C-peptide concentration and duodenal SREBP-Ic mRNA abundance, and reduces occurrence of duodenal tumors and colon aberrant crypt foci in azoxymethane-treated male rats. I Nutr Biochem 2006, 1 7:626-34.

37. Linz AL, Xiao R, Parker JG, Simpson PM, Badger TM, Simmen FA Feeding of soy protein isolate to rats during pregnancy and lactation suppresses formation of aberrant crypt foci in their progeny's colons: interaction of diet with fetal alcohol exposure. J Carcinog 2004, 3(I): I4

38. Xiao R, Hennings LJ, Badger TM, Simmen FA: Fetal programming of colon cancer in adult rats: correlations with altered neonatal growth trajectory, circulating IGF-I and IGF binding proteins, and testosterone. J Endocrinol 2007, I 95:79-87.

39. Frank JA, Xiao R, Yu S, Ferguson M, Hennings LJ, Simpson PM, Ronis MJJ, Fang N, Badger TM, Simmen FA: Effect of Shiitake mushroom dose on colon tumorigenesis in azoxymethane-treated male Sprague-Dawley rats. Nutr Res 2006, 26: I38-45.

40. Papanikolaou A, Wang QS, Delker DA, Rosenberg DW: Azoxymethane-induced colon tumors and aberrant crypt foci in mice of different genetic susceptibility. Cancer Lett 1998 , I 30:29-34.

41. Reuber MD: Carcinomas of the colon in Buffalo strain rats given intraperitoneal injections of methylazoxymethanol acetate. Digestion 1976, I4:3 II-8.

42. Ochiai $M$, Watanabe $M$, Kushida $H$, Wakabayashi $K$, Sugimura $T$, Nagao M: DNA adduct formation, cell proliferation and aberrant crypt focus formation induced by PhIP in male and female rat colon with relevance to carcinogenesis. Carcinogenesis 1996, 17:95-8.

43. Kobaek-Larsen M, Fenger C, Hansen K, Nissen I, Diederichsen A, Thorup I, den BM, Vach W, Ritskes-Hoitinga M: Comparative study of histopathologic characterization of azoxymethaneinduced colon tumors in three inbred rat strains. Comp Med 2002, 52:50-7.

44. Fiala ES: Investigations into the metabolism and mode of action of the colon carcinogens I,2-dimethylhydrazine and azoxymethane. Cancer 1977, 40(5 Suppl):2436-45.

45. Jemal A, Siegel R, Ward E, Hao Y, Xu J, Murray T, Thun MJ: Cancer statistics, 2008. CA Cancer J Clin 2008, 58:7I-96.

46. Hong MY, Chapkin RS, Morris JS, Wang N, Carroll RJ, Turner ND Chang WC, Davidson LA, Lupton JR: Anatomical site-specific response to DNA damage is related to later tumor development in the rat azoxymethane colon carcinogenesis model. Carcinogenesis 2001, 22:1831-35.

47. Ma QY, Williamson KE, Rowlands BJ: Variability of cell proliferation in the proximal and distal colon of normal rats and rats with dimethylhydrazine induced carcinogenesis. World J Gastroenterol 2002, 8:847-52.

48. Schmitt E, Stopper H: Estrogenic activity of naturally occurring anthocyanidins. Nutr Cancer 200I, 41:145-9.

\section{Pre-publication history}

The pre-publication history for this paper can be accessed here:

\section{http://www.biomedcentral.com/1471-230X/9/67/pre} pub 